\title{
A Gestão da Produção em Firmas Agroindustriais
}

\author{
Mário O. Batalha \\ Penido Sthalberg
}

Universidade Federal de São Carlos - UFSCar

Departamento de Engenharia de Produção - DEP

Grupo de Estudos e Pesquisas na Agroindústria - GEPAI

Via Washington Luiz, Km 235

Caixa Postal 676

13565-905 - São Carlos - SP

Palavras-chave: Gestão da produção, agroindustria.

\section{RESUMO}

Este trabalho tem por objetivo principal discutir a aplicação das duas principais filosofias atuais de gestão da produção (just-in-time e just-in-case) ao caso das empresas agroindustriais. O trabalho divide-se em duas partes principais.

Após uma breve introdução, a primeira parte busca evidenciar as especificidades das firmas agroindustriais em relação aos seus processos de produção, de fornecimento em matérias-primas e de distribuição. Estas especificidades são o resultado de vários fatores, dentre os quais pode-se destacar:

- variações sazonais da produção agrícola;

- variações de qualidade na produção agrícola;

- perecibilidade das matérias-primas agrícolas;

- normas de controle de qualidade (sanitárias) estritas,

- variações sazonais no consumo de certos alimentos;

- limitações importantes no ciclo de comercialização dos alimentos (DLV - Datas Limite de Venda).

A segunda parte considera estas especificidades para discutir a problemática da gestão dos fluxos de produção nas empresas agroindustriais. Ainda nesta parte, comenta-se sobre a maior ou menor aplicabilidade dos sistemas tipo MRP e KANBAN a estas firmas.

A parte final do artigo encerra algumas conclusões sobre a questão levantada, além de apresentar algumas orientações para pesquisas futuras. 


\section{Introdução}

O sistema agroindustrial (SAI) brasileiro é responsável por parcela importante da atividade econômica brasileira. Em 1988 ele empregava $23 \%$ da população ativa e era responsável por mais de $30 \%$ do PIB (Jank, 1990). As agroindústrias alimentares representam um importante elo das cadeias produtivas que compõem este sistema (Batalha, 1993). Em 1985 elas representavam 13,3\% dos empregos distribuídos em $20,8 \%$ das indústrias nacionais (ABIA, 1992).

Apesar desta importância inconteste, 0 número pouco expressivo de trabalhos que abordam a adaptação das modernas técnicas de gerenciamento (gestão da produção, marketing, gestão da qualidade, controle de custos industriais, etc) às especificidades deste conjunto de indústrias parece refletir um relativo descaso dos pesquisadores para com esta problemática. Somente num período recente, com o surgimento de alguns grupos de pesquisas espalhados por diferentes Universidades brasileiras, a comunidade acadêmica parece ter despertado para as potencialidades desta área de pesquisa. Porém, cabe ressaltar que, mesmo com o interesse crescente que o assunto vem suscitando, o aprimoramento das ferramentas de gestão das atividades intemas das firmas agroindustriais continua sendo negligenciado e pouco estudado, visto que uma parcela expressiva dos esforços dos pesquisadores está sendo canalizado para analisar, compreender e propor recomendações para o bom funcionamento dos ditos "complexos agroindustriais". Neste caso, a unidade de análise não é a firma em si mesma, mas os complexos vistos através dos seus mecanismos de interação e regulação, sejam eles internos ou externos (as relações entre firma, cadeia, complexo e sistema agroindustrial podem ser vistos em Batalha, 1993).
Neste sentido, este trabalho evidenciará como as especificidades que envolvem as agroindústrias em relação aos seus processos de produção, de abastecimento em matériasprimas (MP) e de distribuição, podem condicionar a aplicação das duas principais filosofias atuais de gestão da produção (just-in-time e just-in-case) às suas unidades fabris.

\section{Algumas Especificidades das Firmas Agroindustriais Alimentares}

Além dos aspectos ligados às especificidades dos seus circuitos de produção, distribuição e abastecimento em MP as firmas agroindustriais também apresentam particularidades em relação ao meio-ambiente socio-econômico que as envolvem. Por um lado, elas se defrontam com fornecedores de MP, pertencentes ao mundo rural, com peculiaridades bem específicas. Por outro lado, elas devem atender consumidores que devem necessariamente se alimentar para sobreviver. Este importante jogo de interesses gera constantes intervenções do governo nos mercados, como forma de tentar garantir (?) um abastecimento alimentar conveniente para a população.

A despeito dos esforços para padronizar e regularizar (diminuição da sazonalidade) a produção agrícola e animal, as firmas agroindustriais ainda se defrontam com problemas relativos à variabilidade na qualidade e na disponibilidade de suas MP de base. Numa indústria onde a MP geralmente representa uma parcela importante da estrutura de custos dos produtos, o controle estrito deste fluxo de abastecimento é muito importante. As variações no clima, que independem da vontade do 
homem, podem afetar sobremaneira a qualidade e a quantidade da produção agrícola, atingindo, desta forma, as agroindústrias.

A amplitude da variação sazonal no abastecimento em MP (mais ou menos importante segundo o produto em questão) pode conjugar-se com uma variação sazonal no consumo dos produtos finais, que pode, por sua vez, ser defasada ou não em relação à sazonalidade da MP. Este fato pode complicar ainda mais o problema de flexibilidade estática das ferramentas de produção das agroindústrias. Face a estes problemas, a indústria pode ser levada a instalar uma capacidade de produção capaz de atender as MP que devem, na safra, ser absolutamente processadas sob pena de se deteriorarem, mas que, em alguns periodos do ano, funciona com uma enorme capacidade ociosa. A defasagem entre o aumento da oferta em MP, e o aumento do consumo de produtos acabados coloca a empresa face ao dilema da formação de estoques para atender os picos de consumo, e todos os encargos gerados pela detenção de estoques elevados.

Por outro lado, o número relativamente baixo de matérias-primas de base, utilizadas por grande parte das agroindustrias, aliado, em grande parte dos casos, a processos continuos de produção, facilita a tarefa de sequenciamento e de controle do fluxo de produção.

A pericibilidade das MP e dos produtos finais são características que afetam uma grande parte das agroindústrias. O processo de industrialização deve ser o mais rápido possível, porque atrasos na produção podem comprometer, de maneira definitiva, a qualidade dos produtos. Os problemas de estoques intermediários de produção, por mais graves que eles sejam para outros setores industriais, assumem, para as agroindústrias, uma impor- tância vital devido a esta perecibilidade.

Uma outra característica que afeta de maneira importante as agroindústrias é aquela ligada à qualidade dos produtos. Como algumas agroindústrias fabricam produtos que serão diretamente consumidos (no sentido literal da palavra) pelo cliente, e que a saúde deste consumidor pode ser seriamente comprometida em função da qualidade deste alimento, o poder público tende a exercer um controle estrito da qualidade final deste produto através de rigorosas normas de produção e comercialização. Se, para alguns setores, a qualidade é uma vantagem concorrencial importante, para as agroindústrias ela é uma questão de sobrevivência. Um problema de não qualidade em um produto qualquer pode afetar de maneira importante uma imagem de marca solidamente implantada no mercado, comprometendo-a de maneira definitiva. Dificilmente um consumidor que viu sua saúde prejudicada pela ingestão de um produto deteriorado ou contaminado, arriscaria novamente, se pudesse evitar, a compra de tal produto.

Além dos problemas devidos à natureza intrínseca dos alimentos, as agroindústrias se defrontam com distribuidores cada vez mais poderosos. As exigências dos distribuidores também condicionam a gestão da produção das agroindústrias. Assim, exigências a nível da embalagem (uma promoção especial, por exemplo) obrigam as agroindústrias a trabalhar, em alguns casos, sob encomenda. Estas exigências, conjugadas ao fato de que os distribuidores querem vender um produto o mais "fresco" possivel, e contar com uma durabilidade na prateleira a mais longa possível, faz com que as agroindústrias tendam, cada vez mais, a trabalhar dentro da filosofia just-in-time. Cabe ressaltar que estes últimos 
aspectos não são somente do interesse do distribuidor, mas também do fabricante, que deve tentar preservar a imagem de marca do seu produto.

\section{A Gestão da Produção nas Agroindústrias}

Para gerir os seus fluxos de produção, as empresas podem utilizar um sistemajust-incase (fluxo "empurrado" por um plano diretor de produção), um sistemajus-in-time (fluxo "puxados" pelos pedidos), ou ainda uma combinação destes dois. Cada uma destas duas "filosofias" de gestão se traduz por técnicas, ferramentas e metodologias que lhes são próprias.

\section{O just-in-case e o MRP.}

As modernas ferramentas dos sistemas just-in-case são baseadas, sobretudo, nos conceitos do MRP (Materials Requirements Planning). A maioria dos softwares integrados de gestão da produção são inspirados nos princípios do MRP.

O MRP é um conceito de gestão da produção desenvolvido nos Estados Unidos durante os anos 60. Este conceito evoluiu, no fim dos anos 70, para o conceito de MRP 2 (Material Resources Planning). O método MRP, em todas as suas variantes, é o mais utilizado nas empresas ocidentais de hoje. Sua aplicação é feita, principalmente, através de várias centenas de softwares disponiveis no mercado. Estes sistemas são, em geral, difíceis de gerir e demandam um suporte em informática importante.
O conceito MRP é baseado na constatação de que uma indústria tem dois tipos de necessidades de material: as necessidades dependentes $\mathrm{e}$ as necessidades independentes.

- Necessidades dependentes: são geradas pelas necessidades independentes e podem ser calculadas pela decomposição dos produtos finais em sub-conjuntos, peças, matériasprima, etc. Este cálculo é o motor do MRP e sua vantagem principal.

- Necessidades independentes: são representadas por produtos que a empresa comercializa no mercado. A previsão destas necessidades baseia-se nas previsões de vendas.

Assim, o MRPé particularmente bem adaptado às indústrias que fabricam produtos tendo um grande número de componentes.

Convém ressaltar que, na lógica MRP, não são os pedidos que "disparam" a fabricação de um artigo. A produção avança segundo um "Programa Mestre de Produção" (PMP) estabelecido geralmente a partir das previsões de venda. Como consequência, a produção é "empurrada" de "montante para jusante".

A lógica de funcionamento do MRP tem uma "vocação" natural para criar estoques. Ele é um sistema construído ao redor da necessidade de aglomerar as necessidades oriundas dos pedidos, com o objetivo de obter séries econômicas de fabricação que diminuam os custos de produção associados a determinadas máquinas que apresentam custos de funcionamento (ou de regulagem) particularmente altos. Ora, a perecibilidade de uma grande parte das matérias-primas envolvidas na produção agroindustrial não permite a formação de estoques intermediários. Para estas empresas a utilização de um sistema MRP 
padrão não se justifica.

A fabricação de produtos em processo contínuo se adapta mal à ótica utilizada pelo MRP. Uma parte expressiva das agroindústrias utilizam justamente este tipo de processo de fábricação.

O cálculo das necessidades em componentes, como forma de facilitar o sequenciamento e o processo de abastecimento em MP é outra das grandes vantagens do MRP. Para algumas agroindústrias estes cálculos não são um problema maior porque elas fabricam produtos pouco complexos, (envolvendo poucas MP de base) no que se refere ao número de componentes.

A perecibilidade, as variações climáticas, a amplitude da sazonalidade e o problema de padronização da produção agrícola perturbam as previsões e a gestão dos estoques de MP. Para o MRP os estoques disponiveis são dados físicos indispensáveis para a planificação da produção (é preciso notar que para algumas agroindústrias é a chegada da MP que dá início à fabricação e não o inverso).

Por outro lado, o just-in-case pode ser válido para alguns tipos de agroindústria. Em todos os casos onde a previsão de estoques de matéria-prima e a previsão de vendas é possível e confiável, pode-se utilizar uma política de produção just-in-case. Isto não quer, absolutamente, dizer que esta é a filosofia de gestão mais indicada. Cada caso deve ser estudado segundo suas características próprias.

Convém, ainda, destacar que as caracteristicas de sazonalidade e perecibilidade de várias MP agrícolas pode levar as agroindústrias a trabalharem emjust-in-case. Na verdade, as indústrias que trabalham com MP pereciveis devem iniciar o processo de fabricação tão logo elas cheguem à fabrica.

Os serviços de manutenção e os aspectos ligados à qualidade são considerados como importantes na filosofia just-in-case, mas não são objetos de controle direto do MRP. Ora, para as agroindústrias, como já foi comentado, o aspecto qualidade reveste-se de uma importância vital.

\section{O just-in-time na agroindústria}

Durante os anos 70 apareceu uma outra "filosofia" de produção que se opunha a gestão da produção do tipo "empurrar". É a produção do tipo "puxar" ou produçãojustin-time.

Foi no Japão que esta nova filosofia de gestão atingiu maior sucesso, e foi através das indústrias japonesas que ela se disseminou pelo ocidente. $O$ exemplo mais conhecido foi o sistema desenvolvido pela Toyota e que ficou conhecido sobretudo pelo seu sistema de informações do tipo Kanban.

Dentro da lógica de produção just-in-time não é o Programa Mestre de Fabricação que deslancha a fabricação. Neste caso, são as encomendas e a demanda dos centros de produção que deslancham a fabricação.

Cabe ressaltar que o just-in-time não é somente um sistema de gestão de produção. Seus objetivos vão muito além. Assim, não se deve confundir o sistema Kanban (sistema de infomações utilizadas para a gestão da produção) e o just-in-time. O Kanban é somente uma ferramenta do just-in-time. Uma indústria pode, por exemplo, utilizar a "filosofia" just-in-time (JIT) sem utilizar o sistema de informações Kanban. 
Uma das ações necessárias à implantação do JTT é a formação de linhas de produção e/ ou células flexíveis de produção. Isso visa, entre outras, dar mais fluidez e flexibilidade aos fluxos de produção. No caso das agroindústrias elas já fabricam, em grande parte, seus produtos em linhas de produção, o que facilita a implantação do JIT.

O controle da qualidade é outro conceito importante à implantação do JIT. Os produtos agroindustriais, como já foi visto, sempre foram, por natureza, controlados ao nivel qualidade, seja este controle externo ou interno à empresa.

A perecibilidade de alguns produtos agroindustriais incita as agroindústrias a trabalharem em JIT. Os distribuidores fazem pressão para receber produtos com DLV a mais longa possivel, o que leva as agroindústrias a diminuirem cada vez mais os seus prazos de entrega. Assim, várias agroindústrias já trabalham en JIT, mesmo sem perceber.

As agroindústrias trabalham, geralmente, com processos de produção curtos, o que facilita o funcionamento em JIT. O ciclo de fabricação curto proporciona respostas mais rápidas às encomendas.

A "diferenciação retardada de produtos" (Tarondeau, 1982) é um artifício utilizado pelo JIT para que o ciclo industrial da fábrica seja compatível com o prazo de entrega ao cliente. Este conceito é largamente utilizado nas agroindústrias. Os produtos agroindustriais, por sua própria natureza, prestam-se bem a esta estratégia de produção.

A polivalência do pessoal é outra característica do JIT. Para as agroindústrias a aplicação deste principio pode ser problemática. A troca de posto de trabalho pelos operários ao longo de uma linha, ou de uma seção de fabricação para outra, é problemática devido ao perigo de contaminação que isto pode oferecer aos produtos. Na verdade, o grau de exigência em termos de higiene sanitária pode variar ao longo de uma linha de produção. Assim, um operário que troca de posto, na mesma jornada de trabalho, pode, se não tomar as precauções devidas, tornar-se um agente de contaminação em todas as etapas de fabricação.

A planificação da produção em um sistema JIT é, geralmente, feito por três meses, e atualizado no mínimo a cada semana. Esta planificação, em um sistema MRP é feita uma vez por ano, e as modificações são trabalhosas de serem feitas. Esta flexibilidade de planificação no sistema JIT combina bem com as caracteristicas das agroindústrias, devido a sazonalidade do consumo e dos problemas de abastecimento em MP.

\section{Não Existem}

\section{Soluções Prontas}

Nenhum dos dois sistemas de produção apresentados podem ser adotados pelas agroindústrias sem as adaptações necessárias. As adaptações devem ser feitas caso a caso, segundo as especificidades da indústria estudada.

A "tendência" das agroindústrias em trabalhar no sistema JIT não impede que o sistema JIC possa ser interessante para algumas destas empresas. Na verdade, pode-se conceber sistemas de gestão mistos onde a produção é "empurrada" até a estabilização da MP e, após esta estabilização, "puxada" pelos pedidos (Floriot, 1992). Este é, por exemplo, o caso dos laticínios. Nestas indústrias o fluxo pode 
ser empurrado pela chegada da MP (perecível e sujeita a sazonalidade). Porém, a empresa tem a possibilidade de secar este leite, transformando-o em leite em pó. A partir deste ponto, a indústria pode trabalhar em função dos pedidos recebidos.

Finalmente, cabe relembrar que um bom sistema de gestão da produção ajuda a pilotar e a controlar uma organização, mas não resolve todos os problemas de ineficácia produtiva. Um bom sistema de gestão da produção deve caminhar junto com tecnologias de processo adequadas e um pessoal bem formado e motivado. A escolha do processo de gestão da produção melhor adaptado deve, necessariamente, levar em consideração as caracteristicas do processo industrial e os objetivos estratégicos da firma.

\section{Referências Bibliográficas}

JANK, Marcos. A inserção do Brasil e do setor cooperativo no mercado mundial de produtos agroindustrializados. USP/ ESALQ, 1990, São Paulo.
BATALHA, Mário O. La notion de filière comme outil d'analyse stratégique: le cas des matières grasses à tartiner au Brésil. Tese de Doutorado IGIA/INPL, 1993, Paris.

ABIA. A indústria brasileira de alimentação hoje. abril/92.

FLORIOT, Jean-Louis. Les stratégies industrielles et la maitrise des flux en industries agro-alimentaires. Revue Economie \& Gestion Agro-alimentaire ${ }^{\circ} 24$, Cergy-Pontoise, França, 1992.

TARONDEAU, Jean-Claude. Produits et technologies - Choix politiques de l'entreprise industrielle. Dalloz, 1982, Paris.

GIARD, Vincent. Gestion de la production. Economica, 1989, Paris. 